\title{
Morphological and Numerical Characteristics of the Southern Chinese Dentitions. Part IV: Traits in the Primary Dentition
}

\author{
Nigel M. King*,1, S. Tongkoom ${ }^{2}$ and H.M. Wong ${ }^{3}$ \\ ${ }^{I}$ Professor in Paediatric Dentistry, Faculty of Dentistry, The University of Hong Kong, Hong Kong SAR, China \\ ${ }^{2}$ Formerly postgraduate student in Paediatric Dentistry, Faculty of Dentistry, The University of Hong Kong, Hong Kong \\ SAR, China \\ ${ }^{3}$ Assistant Professor in Paediatric Dentistry, Faculty of Dentistry, The University of Hong Kong, Hong Kong SAR, \\ China
}

\begin{abstract}
Aim: To investigate the prevalence of twelve dental traits in the primary dentition of southern Chinese and compare to these figures with those from different ethnic groups.

Materials and Methods: The material used in the study consisted of study casts collected from 936 randomly selected 5year-old children (493 males and 443 females) in Hong Kong. The anomalies were assessed using diagnostic criteria that have been most often been cited in the published literature.

Results: Of the twelve dental traits studied, the prevalence figures of seventh accessory cusp (89.0\%), distal trigonid crest $(33.5 \%)$ and metaconid ridge $(84.0 \%)$ in the southern Chinese children were higher than reported for other ethnic groups. The prevalence figures for distinct and strong types of protostylid $(13.7 \%$ and $0.9 \%)$, in this study, were also found to be higher than for other populations. However, the prevalence of deflecting wrinkle was $63.0 \%$ which was the lowest reported for Mongoloids. The prevalences of double lingual tubercle $(22.5 \%)$ and "Y" type of occlusal groove pattern $(80.1 \%)$ in southern Chinese children were found to be lower then for other ethnic groups.

Conclusion: Higher prevalences of seventh accessory cusp, distal trigonid crest and metaconid ridge can be considered to be characteristics of the southern Chinese primary dentition.
\end{abstract}

Keywords: Dental traits, primary dentition, southern Chinese.

\section{INTRODUCTION}

Many morphological variables in the teeth have been identified both in the permanent and primary dentitions. Anthropologists have used expression frequencies of morphological characteristics to examine relationships between populations. This is possible because the expression of each of these dental traits is genetically modulated $[1,2]$. Moreover, one population may not be characterized by a single trait, but by a complex of several racial features [3].

The metrical and non-metrical characters of the permanent dentition have been amply documented for modern human populations; however, relatively few studies have been conducted to investigate the primary dentition. Studies of the primary dentition have reported the prevalence of dental traits in Eskimo [4, 5], Japanese [4-7], north American whites [3, 8], and southern African blacks [9]. Nevertheless, no study has ever been performed on Chinese, yet they comprises a quarter of the world's population. Therefore, it was

*Address correspondence to this author at the Paediatric Dentistry, Faculty of Dentistry, The University of Hong Kong, 2/F, Prince Philip Dental Hospital, 34 Hospital Road, Hong Kong SAR, China; Tel: +852 28590253;

Fax: +852 25593803; E-mail: profnigelking@mac.com considered to be of great value to gather baseline data on the prevalence of the various dental traits in the primary dentition of Chinese children, and to compare these data with those of other ethnic groups.

However, before any valid data can be gathered, the diagnostic features and classifications of these dental traits need to be determined so as to ensure accurate and consistent recording of data and further to permit appropriate comparison between investigators. Although published literature on dental traits in the primary dentition is limited, it seems that variation in the primary dentition may also exist between racial groups, and even sub-racial groups [5, 7].

The aims of this study were to determine the prevalence of various dental traits, such as shovelling, lingual tubercle, double fold, Carabelli's trait, protostylid, occlusal groove pattern, sixth accessory cusp, seventh accessory cusp, deflecting wrinkle, distal trigonid crest, metaconid ridge and triangular shape in the primary dentition of five years old southern Chinese children in Hong Kong. By comparing these data with those on other populations, it was intended to determine if the primary dentition of the southern Chinese has any features that may characterize this dentition. 


\section{MATERIALS AND METHODS}

\section{Study Sample}

The prevalence data for dental traits in the primary dentition were based on plaster casts of 936 children (443 girls and 493 boys), which had been obtained from a randomly selected sample of 5 years old southern Chinese children in Hong Kong. The sampling method was described fully in Part III of this series of papers.

\section{Method of Examination}

During the studying of the dental casts, individual teeth were examined under an illuminated magnifying glass (x3) to diagnose the presence or, absence of a trait. The illustrated versions of the various classifications of the twelve traits, and a list of the teeth upon which they could be expected to occur, was prepared to enhance the accuracy of the diagnoses and to maintain the level of examiner reliability. The reasons for omitting some teeth from the investigation were: (i) poor quality or of the study cast; (ii) chipped or broken teeth; (iii) wear or attrition; (iv) gross caries; and (v) restorations.

\section{Method of Counting}

All of the teeth were examined for evidence of each dental trait. Following statistical analysis, if no statistically difference was found between the data for the right and the left sides, the analysis was made using tooth on the right side; only if a tooth was absent, or omitted were data used for the tooth on the left side.

\section{Reproducibility}

Approximately $10 \%(\mathrm{n}=93)$ of the casts were randomly selected by a computer programme for re-examination three months after the first examination. All of the examinations were conducted by one previously trained and calibrated examiner.

\section{Diagnostic Criteria}

There were twelve dental traits which, according to the published literature, can be expected to be found in the primary dentition:

\section{Shovelling}

Shovelling was expressed as a prominence of the proximal marginal ridges in relation to the lingual fossa, or a concavity of the lingual surface between the marginal ridges and the linguo-gingival ridges or cingulum of the incisor or canine teeth. Shovelling was classified according to Hanihara [4], in which the maxillary central and lateral incisors, and the maxillary and mandibular canines were considered separately.

\section{Classification for the Maxillary Central Incisor}

Type 0 - No shovelling: Only slight, or no marginal ridges. May be manifest weakly on both mesial and distal aspects or occasionally only on the distal aspect. The latter two variants should not have a concavity between the ridges on the lingual surface.

Type 1 - Semi-shovelling: Lingual ridges present on both mesial and distal sides, but disappearing mid-way in their course so the length is usually about one half the crown height. Concavity of the lingual surface is slight.

Type 2 - Shovelling: Lingual marginal ridges are well developed, clearly defined and reaches closer to the lingual tubercle. Concavity on the lingual surface is distinct.

Type 3 - Shovelling: Lingual marginal ridges and the concavity of the lingual surface are well developed.

\section{Classification for the Maxillary Lateral Incisor}

Type 0 - No shovelling: Lingual marginal ridges are slightly developed. The borders between the ridges and the lingual surface are not clear. Concavity of the lingual surface is indistinct.

Type 1 - Semi-shovelling: Lingual marginal ridges and the concavity of the lingual surface are not clear but the ridge may not extend all the way from the incisal edge to the lingual tubercle.

Type 2 - Shovelling: Shovelling is defined by well developed lingual marginal ridges and the concave lingual surface. The ridges are usually thicker than Type 0 and Type 1 .

Type 3 - Shovelling: Marginal ridges are thicker and the concavity of the lingual surface is greater than Type 2 .

\section{Classification of Maxillary Canine}

Type 0 - No shovelling: Variation includes, (a) no trace of the lingual marginal ridge; (b) only one lingual marginal ridges; (c) three ridges, weak marginal ridges and well developed central ridge; (d) any combination of these.

Type 1 - Semi-shovelling: Lingual ridges are distinctly developed and the central ridge is weakly developed. Lingual surface has limited concavity.

Type 2 - Shovelling: Lingual ridges are well developed and the central ridge is weakly developed. The lingual surface has a distinct concavity.

\section{Classification for the Mandibular Canine}

Type 0 - No shovelling: Lingual marginal ridges if present are only very slight.

Type 1 - Semi-shovelling: Lingual marginal ridges are clearly developed but interrupted by well developed grooves or depressions. Concavity of the lingual surface is shallow.

Type 2 - Shovelling: Lingual marginal ridges are clearer than in Type 1. Lingual surface is completely encircled by well defined marginal ridge. The depth of the inner part of the lingual surface is deeper than Type 1.

Type 3 - Shovelling: The development of the lingual ridges is similar to Type 2, but the depression of the lingual surface is deeper.

\section{Lingual Tubercle}

Lingual tubercle is considered to be a single, or double protuberance arising from the cingulum of the lingual surface of the primary maxillary canine and extending less than half the distance from the cemento-enamel junction to the incisal edge. When a double tubercle is present, the distal tubercle is usually slightly larger than the mesial tubercle [3]. 


\section{Double Fold}

Double fold on the primary maxillary canine is formed by the groove separating the distal marginal ridge and an accessory ridge where the accessory ridge is located between the median ridge and the distal marginal ridge. The groove commences at the basal junction of the accessory and distal marginal ridge and extends towards and terminats at the distal incisal edge. The general appearance is that of a folded and enlarged distal marginal ridge [3].

\section{Carabelli's Trait}

Carabelli's trait occurrs on the lingual surface of the protocone of the primary maxillary second molar and is expressed as either a tubercle of varying size, or as a groove, or pit. The classification of Carabelli's trait of the primary maxillary second molar was based upon the variation reported by Hanihara [4]:

Type 0 - No Carabelli cusp is recognized.

Type 1 - Shallow groove on mesial of lingual surface suggestive of a trace of the pit.

Type 2 - Shallow depression or groove exists without any change in the curvature of the lingual surface.

Type 3 - Depression or pit deeper than Type 2 but no bulge observed.

Type 4 - Expression similar to that of Type 3 but slight eminence on the lingual surface of protocone.

Type 5 - Eminence greater than Type 4. However, the Carabelli cusp extends smoothly onto the rest of lingual surface without interruption.

Type 6 - Carabelli cusp is completely encircled by a groove forming a $5^{\text {th }}$ cusp.

Type 7 - Carabelli cusp well developed and might be larger than the hypocone.

\section{Protostylid}

The protostylid was expressed as an accessory cusp located on the buccal surface of the protoconid of the primary mandibular second molar. The classification for the protostylid, of the mandibular second molar, was based upon that of Hanihara [4]:

Type 0 - Absent: Buccal groove is straight and no trace of irregularity.

Type 1 - Absent: No evidence of protostylid, but the beginning of one is suggested by the curvature and branching of the buccal groove. There may be a small, but distinct pit at the lower end of the buccal groove separating protoconid from the hypoconid and the buccal groove is slightly bent in a distal direction at the point of the pit.

Type 2 - Present 1: Divergence of buccal groove is more developed than Type 3. Small triangular area with tip downwards between the branches of the buccal groove.

Type 3 - Present 2: The two branches of the buccal groove are more developed than Type 3 . Small triangular area with tip downwards between the branches of the buccal groove.
Type 4 - Present 3: A very shallow groove appears at the corner of the buccal surface. The area between this groove and mesial branch of the buccal groove bulges slightly and gives triangular shape with its tip upwards.

Type 5 - Present 4: Triangular area is more strongly developed than Type 5.

Type 6 - Present 5: Protostylid is strongly developed so that the tooth seems to have an extra cusp on the buccal surface.

\section{Occlusal Groove Pattern}

The dryopitchecus occlusal groove pattern of the primary mandibular second molar is formed by the relationship of the basal contacts of the central ridges of the protoconid, metaconid, hypoconid and the entoconid. The classification for the occlusal groove pattern, of the primary mandibular second molar,was adapted from those of Hellman [10] and Jørgensen [11].

Type 1 - "Y" pattern: The metaconid is in basal line contact with the hypoconid.

Type 2 - "+" pattern: Formed by the basal point shaped contact between the protoconid-entoconid and metaconidhypoconid. It cannot be determined with certainly which of the two diagonal pairs of cusps has the most basal contact, or that this contact does not exceed $0.2 \mathrm{~mm}$.

Type 3 - "X" pattern: Formed by the basal linear contact between the protoconid and entoconid.

\section{Sixth Accessory Cusp}

The sixth accessory cusp is the accessory cusp located on the distal surface between the entoconid and the hypoconid of the primary mandibular second molar [5].

\section{Seventh Accessory Cusp}

The seventh accessory cusp is the accessory cusp located on the lingual surface between the metaconid and the entoconid of the primary mandibular second molar. The classification for the seventh accessory cusp, of the primary mandibular second molar, was based upon that of Hanihara [4].

Type 0 - Absent: No trace of the seventh cusp.

Type 1 - Present 1: A very weak and short groove which extends downwards from the lingual ridge of the metaconid.

Type 2 - Present 2: Groove on the metaconid is more definite. Small cusp-like formation is present.

Type 3 - Present 3: Seventh cusp is well developed and looks like an independent accessory cusp. It is small when compared with either metaconid or entoconid.

\section{Deflecting Wrinkle}

The deflecting wrinkle is formed by the configuration of the median ridge of the metaconid which shows a strong development in both length and breadth and curves distally in the central part of the occlusal surface to contact the hypoconid of the primary mandibular second molar [5].

\section{Distal Trigonid Crest}

The distal trigonid crest is the structure which connects, without interruption, the tip of the metaconid with the proto- 
conid on the primary mandibular second molars. Thus, the occlusal surface is clearly divided into two parts, the trigonid and the talonid [4].

\section{Metaconid Ridge}

The metaconid ridge is formed by the well developed central ridge in both length and breadth of the metaconid on the primary mandibular second molar [4].

\section{Triangular Shape}

The triangular shape trait occurs in the primary mandibular first molar. The occlusal surface pattern is triangular in shape due to the fusion of the metaconid and the entoconid [4].

\section{Prevalence Data Review}

In order to compare the prevalence data from this study with those of other studies the literature and data from studies published between 1930 and 2009, which were related to dental traits in the primary dentition, were sourced using PubMed and hand searches. The key words used for the PubMed searches were dental traits, primary dentition, shovelling, lingual tubercle, double fold, Carabelli's trait, protostylid, occlusal groove pattern, sixth accessory cusp, seventh accessory cusp, deflecting wrinkle, distal trigonid crest, metaconid ridge and triangular shape. The reference lists of the articles retrieved from the electronic database were subsequently hand searched to identify additional articles that might provide information relevant to the objectives of this study. It was impractical to perform a systematic review because the methodology used in the published studies varied, thus preventing valid statistical analyses.

\section{RESULTS}

A total of 93 of the casts were re-examined to measure the examiner reliability for the diagnoses of the various dental traits. The Kappa coefficients were in the range from 0.55 (deflecting wrinkle) to 0.92 (triangular shape). As there was no statistically significant difference between the prevalence figures for the dental traits on the right and the left sides of the jaws, the various analyses were made based on the teeth on the right side, unless these teeth were absent or damaged, in which case the teeth of the left side were used.

Of the twelve dental traits, occlusal groove pattern trait in the primary mandibular second molars occurred in all of the subjects $(100 \%)$. Shovelling was the second commonest trait and occurred in $99.3 \%$ of the girls and $96.8 \%$ of the boys; whereas, double fold occurred in only $11.1 \%$ of the girls and $11.4 \%$ of the boys (Table 1). The comparison of the prevalence figures of the various dental traits observed in this study, with those of other studies are shown in Tables $\mathbf{2}$ to 13. There were higher prevalence figures for shovelling, protostylid, seventh accessory cusp, deflecting wrinkle, distal trigonid crest, metaconid ridge and triangular shape for Mongoloids groups, including southern Chinese, than for Caucasians. The prevalence figures for seventh accessory cusp $(89.0 \%)$, distal trigonid crest $(33.5 \%)$ and metaconid

Table 1. The Mouth Prevalence of the Various Dental Traits in the Primary Dentition of 936 Five Years Old Southern Chinese Girls and Boys in Hong Kong

\begin{tabular}{|c|c|c|c|c|c|}
\hline \multirow{2}{*}{ Dental trait } & \multirow{2}{*}{$\begin{array}{l}\text { Tooth type } \\
\text { examined }\end{array}$} & \multicolumn{2}{|c|}{ Girls $(N=443)$} & \multicolumn{2}{|c|}{ Boys $(N=493)$} \\
\hline & & $\mathbf{n}$ & $\%$ & $\mathbf{n}$ & $\%$ \\
\hline Shovelling & $i^{1,2}, c^{-}, c$ & 440 & 99.3 & 477 & 96.8 \\
\hline \multicolumn{6}{|l|}{ Lingual tubercle } \\
\hline single & $\mathrm{c}^{-}$ & 94 & 21.2 & 103 & 20.9 \\
\hline double & $\mathrm{c}^{-}$ & 100 & 22.6 & 111 & 22.5 \\
\hline Double fold & c. & 49 & 11.1 & 56 & 11.4 \\
\hline Carabelli's trait & $\mathrm{m}^{2}$ & 361 & 81.5 & 391 & 79.3 \\
\hline Protostylid & $\mathrm{m}_{2}$ & 405 & 91.4 & 453 & 91.9 \\
\hline \multicolumn{6}{|l|}{ Occlusal groove pattern } \\
\hline $\mathrm{Y}$ & $\mathrm{m}_{2}$ & 360 & 81.2 & 390 & 79.1 \\
\hline+ & $\mathrm{m}_{2}$ & 42 & 9.5 & 55 & 11.2 \\
\hline $\mathrm{X}$ & $\mathrm{m}_{2}$ & 41 & 9.3 & 48 & 9.7 \\
\hline Sixth accessory cusp & $\mathrm{m}_{2}$ & 147 & 33.2 & 232 & 47.1 \\
\hline Seventh accessory cusp & $\mathrm{m}_{2}$ & 388 & 87.6 & 445 & 90.3 \\
\hline Deflecting wrinkle & $\mathrm{m}_{2}$ & 239 & 54.0 & 351 & 71.2 \\
\hline Distal trigonid crest & $\mathrm{m}_{2}$ & 168 & 37.9 & 146 & 29.6 \\
\hline Metaconid ridge & $\mathrm{m}_{2}$ & 367 & 82.8 & 444 & 90.1 \\
\hline Triangular shape & $\mathrm{m}_{1}$ & 49 & 11.1 & 115 & 23.3 \\
\hline
\end{tabular}


ridge $(86.6 \%)$ for the southern Chinese children were higher than reported for the other ethnic groups (Tables 9, 11 and 12). Moreover, the prevalence figures for distinct and strong types of protostylid $(13.7 \%$ and $0.9 \%)$ in this study were found to be higher than for other populations (Table 6). Although deflecting wrinkle was regarded as characteristic of Mongoloids, the prevalence in southern Chinese children was the lowest among the various Mongoloid populations, at $63.0 \%$ (Table 10). The prevalences of double lingual tubercle $(22.5 \%)$ and the "Y" type of occlusal groove pattern $(80.1 \%)$ in southern Chinese children were even lower than for other ethnic groups (Tables 3 and 7).

\section{DISCUSSION}

This study was based on the high quality plaster study casts of a randomly selected representative sample of southern Chinese children. The disadvantage of examining casts of teeth, rather than the actual teeth is that the trait may be obscured by damage cause during storage, or due to a poor quality impression. Therefore, skillful impression taking and careful storage of casts are important to preserve the size of the sample. However, the advantages were that all of the tooth surfaces could be observed easily and there were no time constraint, or patient co-operation problems involved as can occur in an oral examination of a young child. Moreover, the examination of casts under an illuminated magnifying glass made some of the traits, especially the weaklydeveloped types, much easier to see than they would have been in the mouth; for example the pit type of Carabelli's trait. Consequently, it is theoretically possible that the magnification and ease of examination may have led to the recording of a greater number of characteristics.

In an attempt to allow for comparison with published data of dental traits in the primary dentition, as far as possible, the classification of, or one closely based upon that of Hanihara [4] were used rather than trying to modify other classifications for the permanent teeth. The diagnostic criteria and classification used for the lingual tubercle, Carabelli's trait, protostylid, occlusal groove pattern, seventh accessory cusp, distal trigonid crest, metaconid ridge and triangular shape were satisfactory because they were clear and easy to apply; thus, they can be recommended for use in future investigations.

However, some problems did occur with the diagnosis of shoveling. No observations were made on the primary mandibular incisors because the characteristics in these teeth were usually too weak to be classified into the different types of shovelling. In many instances a clear diagnosis could not be made, even for the maxillary incisors and maxillary and mandibular canines, due to the numerous intermediate types and the weak expression of the shoveling trait, especially in the mandibular canines.

The findings of this study support the suggestion of Scott [12], for the permanent dentition, that double fold is an example of a dental trait that exhibits a continuous size variation on the accessory ridge. Therefore, it would seem appropriate that a classification be developed to record the variation in size of the accessory ridge rather than simply to record it as absent or present, for this may have evolutionary implications.
No attempt was made to classify the sixth accessory cusp trait into different types, based upon the size of the cusp and, as yet, no reliable method has been found to distinguish the presence of the entoconid in the absence of the hypococonid. Moreover, deflecting wrinkle was not classified into the different types, based on the size of the ridge, because difficulties were experienced in trying to differentiate between the intermediate types.

The methods used to count dental traits in a population are based upon a count per tooth, or per individual. Most investigators have used the individual count method, as proposed by Scott (1980) [13], which records the fullest expression of a given trait on either the right or left side of the jaw. When a tooth was missing or damaged the degree of expression on the other side was scored. In this study, the data for the right and left side were tested statistically in the same manner as reported by Hanihara [6] and Kuusk [14]. Since there were no statistically significant differences between the two sides, the data for the right side were used in the final analysis. Thus, the data from this study are comparable to those of the majority of the published studies. This approach which was justified on a statistical basis, avoided arbitrarily deciding to use only the data for one side. Thus, it overcame the rather inconsistent approach of Scott (1980) [13] who also examined all of the teeth, but then discard data for the less severely affected side. It also avoided the adverse effects on the data of traits that were asymmetrically distributed.

The various traits will be discussed by first considering the physical characteristic, followed by the prevalence of that anomaly, among different populations, in order to identify any distinctive features in the data for the primary dentition of the southern Chinese.

\section{Shovelling}

This trait is said to be present when the palatal surface of an incisor resembles a shovel due to the combination of a concave lingual surface in association with elevated marginal ridges. The marginal ridges, also called dentales, are usually found on the maxillary incisors, but they can also be found on mandibular incisors [15]. Shovelling is more common in the permanent dentition than the primary dentition [16], and is more frequently observed on the maxillary than the mandibular incisors with the lateral incisors being affected more often than the central incisors in the primary dentition [9].

Some investigators, who have studied shovelling, have used the subjective scale proposed by Hrdlička [15], in which there are four degrees: no shovelling, trace shovelling, semi-shovelling and shovelling. The classifications based on the relative variability of the primary maxillary incisors and canine, and mandibular canines were proposed by Hanihara [4]. Hanihara [3] found that the shovelling trait occurred frequently and was relatively well developed in the Japanese, Pima Indians and Eskimos. The reverse situation was found for American whites, American negroes and Australian Aboriginals. However, it should be noted that the prevalence figures given by Hanihara [3, 8], Kuusk [14], Lukacs and Walimbe [17], and Sciulli [18] may not be representative of the populations as a whole because they were derived from small, non-representative samples, most especially those of Lukacs and Walimbe [17] and Sciulli [18]. 
Table 2. The Prevalence, Expressed as a Percentage, of the Different Degrees of Shovelling in the Primary Dentition in Published Studies

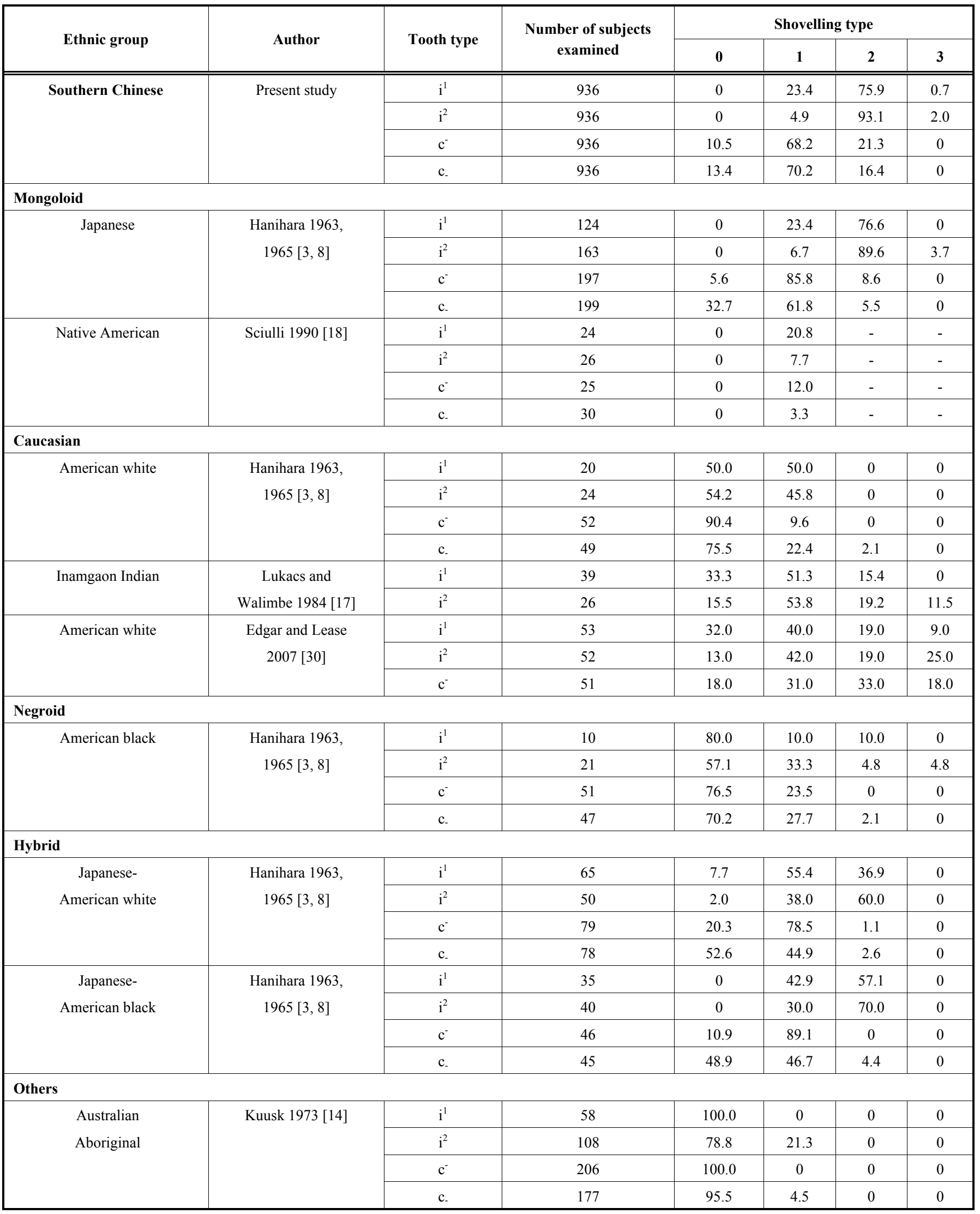


Shovelling and semi-shovelling were found in the maxillary incisors and canines of both jaws. Shovelling was found more frequently in maxillary incisors whereas semishovelling was found more frequently in the canines. Marked shovelling was found to occur only on the maxillary incisors (Table 2). The prevalence of shovelling for southern Chinese children was similar to that for Japanese children [3, 8]. It appears that shovelling occurs much more frequently in Mongoloids than in Caucasians and other populations (Tables 2 and 13). The study of skeletal remains of a late Archaic of Ohio (native American), in which the prevalence of shovelling was found to be even higher than in some Mongoloids, indicated they were a population of northern Asian descent [18]. The findings from the present study support the statement made by Hanihara [5] that shovelling can be considered to be a Mongoloid dental characteristic.

\section{Lingual Tubercle}

Lingual tubercle is a slight rounded elevation on the linguo-gingival ridge of an anterior tooth. Because the lingual tubercle is more frequently observed, and better developed in archaeological remains than in modern man, it is believed to be a derivative of the cingulum and many have significances in the evolution of primates [19,20]. Variation of lingual accessory tubercles were described by Hrdlička [21] as being either single, double or multiple; long and narrow; or short and stumpy [3]. They occur most frequently on canines and to a lesser extend on maxillary incisors [21]. When the trait is expressed as two tubercles the distal one is usually larger than the mesial [3]. Multiple tubercles are rare on the incisors. Jørgensen [11] reported that the tubercle always presented as two short projections, one on either side of the lingual ridge, while the mandibular canine almost never exhibited tubercles.

Although the lingual tubercle is found in all ethnic groups, the degree of development shows marked racial variation. Furthermore, the prevalence of the single tubercle variation has been shown to decrease as the prevalence of double tubercle increases in a population [6, 22]. Population differences for double tubercle are an invariable population characteristic in which the prevalence figures are within the range $43.8 \%$ to $58.8 \%$ [3]. However, the results of Kuusk's [14] study showed that the double tubercle can be regarded as a racial trait of the Australian Aboriginals due to the high prevalence of $75.1 \%$. In the present study, double tubercle occurred slightly more frequently than single tubercle, at $22.5 \%$ and $21.0 \%$ respectively. The prevalence figure for double tubercle in southern Chinese children was lower than for any other populations, see Table 3 .

\section{Double Fold}

The double fold characteristic was reported on the distal border of the lingual surface of the both primary and permanent mandibular canines in Sinanthropus pekinensis [20]. This trait makes the distal marginal ridge appear double because of a groove running between the middle of the two ridges [20]. However, Robinson [23] described a welldefined distal lingual groove and a slight ridge running immediately on the mesial side to the groove on the mandibular canines of Australopithecines.

In the primary mandibular canines of modern man, the lingual ridges are generally poorly developed; but the mesial and distal marginal ridges are slightly better defined than the median ridge. In addition to this, an extra ridge located between the median and the distal marginal ridges may be found. When present, the extra ridge can be better developed than all of the other ridges. A groove separating these two ridges, running up to the distal end of the incisal edge, emerges from a point where the lower terminals of the ridge join together [3].

In the permanent dentition, Scott [12] proposed a classification based upon size. However, in the classification for primary mandibular canines no attempt was made to classify

Table 3. The Prevalence, Expressed as a Percentage, of the Lingual Tubercle Trait on the Primary Maxillary Canines in Published Studies

\begin{tabular}{|c|c|c|c|c|c|}
\hline Ethnic group & Author & $\begin{array}{c}\text { Number of subjects } \\
\text { examined }\end{array}$ & \multicolumn{3}{|c|}{ Tubercle type } \\
\hline Southern Chinese & Present study & 936 & 56.5 & 21.0 & 22.5 \\
\hline \multicolumn{6}{|l|}{ Mongoloid } \\
\hline Japanese & Hanihara 1965 [3] & 194 & 4.1 & 52.1 & 43.8 \\
\hline American white & Hanihara 1965 [3] & 50 & - & - & 48.0 \\
\hline \multicolumn{6}{|l|}{ Negroid } \\
\hline American black & Hanihara 1965 [3] & 51 & - & - & 58.8 \\
\hline \multicolumn{6}{|l|}{ Hybrid } \\
\hline Australian Aboriginal & Kuusk 1973 [14] & 210 & 26.6 & 1.9 & 71.5 \\
\hline
\end{tabular}


according to size because the relief on the lingual surface of the primary canine is less well developed than that of the permanent canine [3].

The prevalence of double fold is relatively low in pimary mandibular canines showing little variance within the range $3.8 \%$ to $9.0 \%[3,14,18]$. Although the southern Chinese exhibited a slightly higher prevalence figure of $11.2 \%$ in this study (Table 4), the data indicate that the inter-population difference seems to be insignificant; thus, the trait can be considered to be an invariable inter-population characteristic $[3,14]$. Moreover, it has been suggested that as the evolution of the human dentition has proceeded, double fold has become increasingly rare [3]. However, no truly representative epidemiological studies have been reported prior to the current study; moreover, the samples from previous studies are generally too small to provide accurate data, especially the skull samples used in the study of native Americans by Sciulli [18].

\section{Carabelli's Trait}

Carabelli's cusp is an additional cusp on the mesiolingual surface of the crown of a maxillary molar. This cusp is found to have variable expressivity such as lobular, cuspoid, ridged and pitted. Morphologically, it varies from an indented surface (ridges and pits) to a full cusp. Although several classifications have been developed to characterize the different expression of Carabelli's trait [4, 11, 24-27], most are for the maxillary first permanent molar which was the key tooth in Dahlberg's classification [28]. Nevertheless, the maxillary second primary molar can also exhibit Carabelli's trait.

Most of the classifications for Carabelli's trait are based on the size of the cusp; hence, there are problems when a variety of grooves, furrows or pits occur. In order to over- come this problem Dahlberg [29] proposed a classification with eight types, ranging from a completely smooth uninvolved surface to a single furrow, a pit, a double furrow, a Y-form and three grades based upon size. Hanihara [4] proposed a classification which also had eight types ranging from groove, pit to cusp. Unfortunately, the different criteria are not directly comparable due to slightly different groupings of the various forms of the trait.

It is difficult to directly compare data from the different published studies because of the differences in the sample sizes and the classifications that were used. Although the findings of Hanihara [8] are frequently quoted they were not from an epidemiological study. Nevertheless, from the summarized data in Table 5 it can be seen that the prevalence of Carabelli's cusp is higher in Caucasians than Mongoloids, including southern Chinese, with the highest prevalence of $39.0 \%$ being for American whites [30]. Due to the higher prevalence in Caucasians, Carabelli's cusp has been considered to be characteristic of the Caucasoid dentition [5].

\section{Protostylid}

The protostylid trait which was first reported by Bolk [31] is seen most commonly on the buccal surface of the mesiobuccal cusp of both primary and permanent molars. The term protostylid or parastyle has been proposed for any anomalous cusps on the buccal surface of maxillary and mandibular premolars and molars [28]. In the primary dentition, the protostylid is found on the buccal surface of the protoconid of the mandibular second molar. The protostylid trait occurs more frequently on the primary than permanent molars [4]. Whenever the protostylid is found on a permanent molar the trait was reportedly present on the primary second molar; however, the reverse situation does not always occur $[4,32]$. The classification of Hanihara [4] recognized

Table 4. The Prevalence, Expressed as a Percentage, of the Double Fold Trait on the Primary Mandibular Canines in Published Studies

\begin{tabular}{|c|c|c|c|c|}
\hline Ethnic group & Author & $\begin{array}{c}\text { Number of subjects } \\
\text { examined }\end{array}$ & \multicolumn{2}{|c|}{ Double fold } \\
\hline \multicolumn{5}{|l|}{ Mongoloid } \\
\hline Japanese & Hanihara 1965 [3] & 200 & 9.0 & 91.0 \\
\hline \multicolumn{5}{|l|}{ Caucasian } \\
\hline American white & Hanihara 1965 [3] & 48 & 4.2 & 95.8 \\
\hline \multicolumn{5}{|l|}{ Negroid } \\
\hline American black & Hanihara 1965 [3] & 47 & 6.4 & 93.6 \\
\hline Japanese-American black & Hanihara 1965 [3] & 45 & 8.9 & 91.1 \\
\hline \multicolumn{5}{|l|}{ Others } \\
\hline Australian Aboriginal & Kuusk 1973 [14] & 175 & 5.7 & 94.3 \\
\hline
\end{tabular}


Table 5. The Prevalence, Expressed as a Percentage, of the Carabelli's Trait on the Primary Maxillary Molars in Published Studies

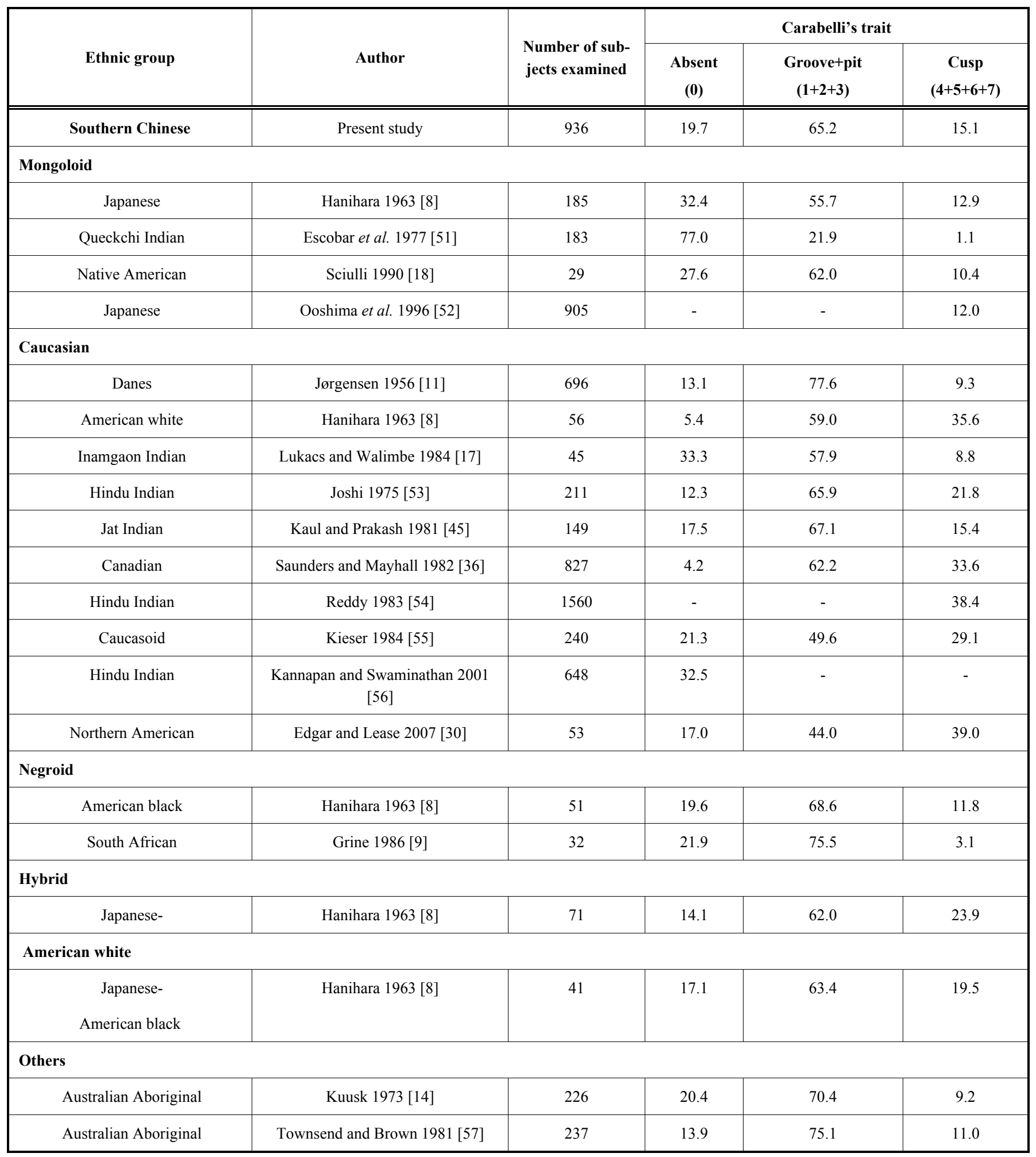

seven types of protostylid which can occur on the primary mandibular second molars.

In Mongoloid populations the protostylid trait occurs in more than $40 \%$ of individuals, while in non-Mongoloid populations the prevalence is generally below $20 \%$ (Table 6 ). Therefore, the protostylid trait has been regarded as a charac- teristic feature of the Mongoloid dentition [7]. The prevalence of protostylid trait was $91.7 \%$ in this study which was slightly higher than for Pima Indian at $89.0 \%$ [7], which is the highest prevalence figure among other Mongoloids. The distinct type of protostylid is rare and the strong type has not been reported in American whites, Negroes or their hybrids (Table 6). However, the distinct and strong types of 
Table 6. The Prevalence, Expressed as a Percentage, of the Protostylid Trait on the Primary Mandibular Second Molars in Published Studies

\begin{tabular}{|c|c|c|c|c|c|c|}
\hline \multirow{2}{*}{ Ethnic group } & \multirow{2}{*}{ Author } & \multirow{2}{*}{$\begin{array}{l}\text { Number of sub- } \\
\text { jects examined }\end{array}$} & \multicolumn{4}{|c|}{ Protostylid trait } \\
\hline & & & $\frac{\text { Absent }}{0+1}$ & $2+3$ & $4+5$ & 6 \\
\hline Southern Chinese & Present study & 936 & 8.3 & 77.1 & 13.7 & 0.9 \\
\hline \multicolumn{7}{|l|}{ Mongoloid } \\
\hline Pima Indian & Hanihara 1968 [7] & 118 & 11.0 & - & - & - \\
\hline Eskimo & Hanihara 1968 [7] & 52 & 32.7 & - & - & - \\
\hline Japanese & Ooshima et al. 1996 [52] & 905 & - & - & - & 0.7 \\
\hline \multicolumn{7}{|l|}{ Caucasian } \\
\hline American white & Hanihara 1968 [7] & 54 & 87.0 & 13.0 & 0 & 0 \\
\hline Inamgaon Indian & Lukacs and Walimbe 1984 [17] & 61 & 98.4 & - & - & - \\
\hline Northern American & Edgar and Lease 2007 [30] & 52 & 90.0 & 10.0 & 0 & 0 \\
\hline \multicolumn{7}{|l|}{ Negroid } \\
\hline American black & Hanihara 1968 [7] & 47 & 83.0 & 14.9 & 2.1 & 0 \\
\hline South African & Grine 1986 [9] & 37 & 83.8 & - & - & - \\
\hline \multicolumn{7}{|l|}{ Hybrid } \\
\hline Australian Aboriginal & Kuusk 1973 [14] & 218 & 83.5 & - & - & - \\
\hline
\end{tabular}

$0+1=$ no protostylid trait, $2+3=$ groove, $4+5=$ triangular shape, $6=$ cusp.

protostylid in this study were $13.7 \%$ and $0.9 \%$ respectively. Therefore, because of their higher prevalences, the distinct and strong types of protostylid may be considered to be features of the primary dentition in southern Chinese children.

\section{Occlusal Groove Pattern}

The dryopithecus occlusal groove pattern, a term introduced by Gregory [33], in the primary mandibular second molar is formed by the relationship of the basal contacts of the central ridges of the protoconid, metaconid, hypoconid and the entoconid [6].

The occlusal groove patterns were classified into two types which were referred to by the letter "Y" and by the plus sign "+" [10]. The basic five cusped pattern was the "Y5" type which was referred to as "dryopithecoid". An additional groove configuration termed the " $X$ " pattern was subsequently added and it was proposed that the cusp number and groove pattern should be considered independently
[11]. Hanihara [6] and Turner [34] adapted the modified classification for their studies.

Hanihara [6] found that the prevalence of the five cusped "Y" type was in the range from $95 \%$ to $100 \%$ in the primary dentition which was greater than in permanent molars. The trait was, at that time, considered to be an invariable population characteristic $[6,14]$. However, in the majority of the previously published studies, the sample sizes were too small to provide statistically representative data. It appears that southern Chinese had a lower prevalence of the "Y" type and a higher prevalence of the " $X$ " type of occlusal groove pattern than for other ethnic groups (Table 7). Nevertheless, more studies are needed to provide higher quality prevalence data for valid comparisons.

\section{Sixth Accessory Cusp}

The sixth accessory cusp is one of the extra cusps that is located on the distal aspect of the occlusal surface between 
Table 7. The Prevalence, Expressed as a Percentage, of the Occlusal Groove Pattern Trait on the Primary Mandibular Second Molars in Published Studies

\begin{tabular}{|c|c|c|c|c|c|}
\hline \multirow{2}{*}{ Ethnic group } & \multirow{2}{*}{ Author } & \multirow{2}{*}{$\begin{array}{c}\text { Number of subjects } \\
\text { examined }\end{array}$} & \multicolumn{3}{|c|}{ Occlusal groove pattern } \\
\hline & & & $\mathbf{Y}$ & + & $\mathbf{x}$ \\
\hline Southern Chinese & Present study & 936 & 80.1 & 10.4 & 9.5 \\
\hline \multicolumn{6}{|l|}{ Mongoloid } \\
\hline Japanese & Hanihara 1956 [6] & 81 & 97.5 & 2.5 & 0 \\
\hline \multicolumn{6}{|l|}{ Caucasian } \\
\hline Jat Indian & $\begin{array}{c}\text { Kaul and Prakash } 1981 \\
\text { [45] }\end{array}$ & 151 & 89.6 & 10.4 & 0 \\
\hline \multicolumn{6}{|l|}{ Negroid } \\
\hline South African & Grine 1986 [9] & 39 & 89.7 & 10.3 & 0 \\
\hline \multicolumn{6}{|l|}{ Hybrid } \\
\hline Japanese-American white & Hanihara 1956 [6] & 60 & 95.5 & 5.0 & 0 \\
\hline Japanese-American black & Hanihara 1956 [6] & 19 & 100.0 & 0 & 0 \\
\hline \multicolumn{6}{|l|}{ Others } \\
\hline Australian Aboriginal & Kuusk 1973 [14] & 194 & 96.9 & 3.1 & 0 \\
\hline
\end{tabular}

the entoconid and the hypoconid of the primary mandibular second molar [6]. The sixth accessory cusp has also been referred to by the following names: tuberculum accessorium, posteriore internum, tuberculum sextum, cusp six and entoconulid. The sixth accessory cusp is derived from a partitioning of the entoconid, as such, it tends to be situated lingual to the central developmental groove. Unfortunately, no reliable method has been found to distinguish the presence of the entoconid in the absence of the hypoconid. Further complications arise because examples can be found where there is a bifurcation or, even a trifurcation of the hypoconid into multiple cuspules in addition to the sixth cusp; this can lead to their misidentification as entoconids. Hanihara [5] only recorded the cusp as being present or absent while Tuner [35] graded the cusps into six types according to size.

The prevalence of the sixth accessory cusp in Japanese has been reported to be higher in primary than in permanent mandibular molars [6]. The prevalence for Canadian children of $1.7 \%$ [36] suggests that the sixth accessory cusp trait is rare among north American Caucasians. The sixth accessory cusp has been considered to be a trait of the Mongoloid dental complex because of its high prevalence in this ethnic group [5]. Kuusk [14] stated that since the difference in the prevalence between the Mongoloids and Australian Aboriginals was so large, the sixth accessory cusp must be considered as a racial characteristic of Australian Aboriginals. In the present study the prevalence figure for the sixth accessory cusp was $40.5 \%$ which is comparable to that for other Mongoloids (36.8\% - 37.7\%), see Table 8 .

\section{Seventh Accessory Cusp}

The seventh cusp has been found in non-human primates [37] as well as in archaeological remains and modern man. Among fossil material it has been found in a number of specimens such as Proconsul africanus, Sivapithecus in- dicus, Indopithecus giganteus and in some species of Dryopithecus, Gigantopithecus, Meganthropus, Sinanthroups, Neanderthal man [38, 39] and Australopithecus [23].

This tubercle, or small cusp, which is located at the marginal border between the metaconid and the entoconid, from which it is separated by a furrow emanating from the marginal border was originally described by Selenka [40], who found this structure on the mandibular molars of a large number of orangutans.

This cusp has been referred to as tuberculum accessorium, mediale internum [40], tuberculum intermedium [41], seventh cusp [10], median lingual accessory cusp [42], and cusp seven [43]. It has been stated that the seventh accessory cusp should only be counted as a cusp if the tip has risen higher than the more or less pronounced secondary groove by which it was separated from the metaconid. Jørgensen [11] Hanihara [4] established a classification according to the developmental stages of the cusp, while Turner [35] based his classification on the size of the cusp.

Inter-population comparisons indicate that the prevalence of the seventh accessory cusp is higher at $73.7 \%$ for Japanese and $79.4 \%$ for Eskimos than for American whites and negroes at $40.7 \%$ and $46.8 \%$ respectively [44]. Therefore, the trait has been considered to be an inter-race variable characteristic and to form part of the Mongoloid dental complex [5]. Further, the prevalence of the seventh accessory cusp among Indian children reported by Kaul and Prakash [45] and Lukacs and Walimbe [46] indicates that southern Asians might be unique in exhibiting a lower prevalence of seventh accessory cusp than other Asians. The prevalence figure obtained in this study was $89 \%$ which is higher than for other ethnic groups (Table 9). This high prevalence, on 
Table 8. The Prevalence, Expressed as a Percentage, of the Sixth Accessory Cusp Trait on the Primary Mandibular Second Molars in Published Studies

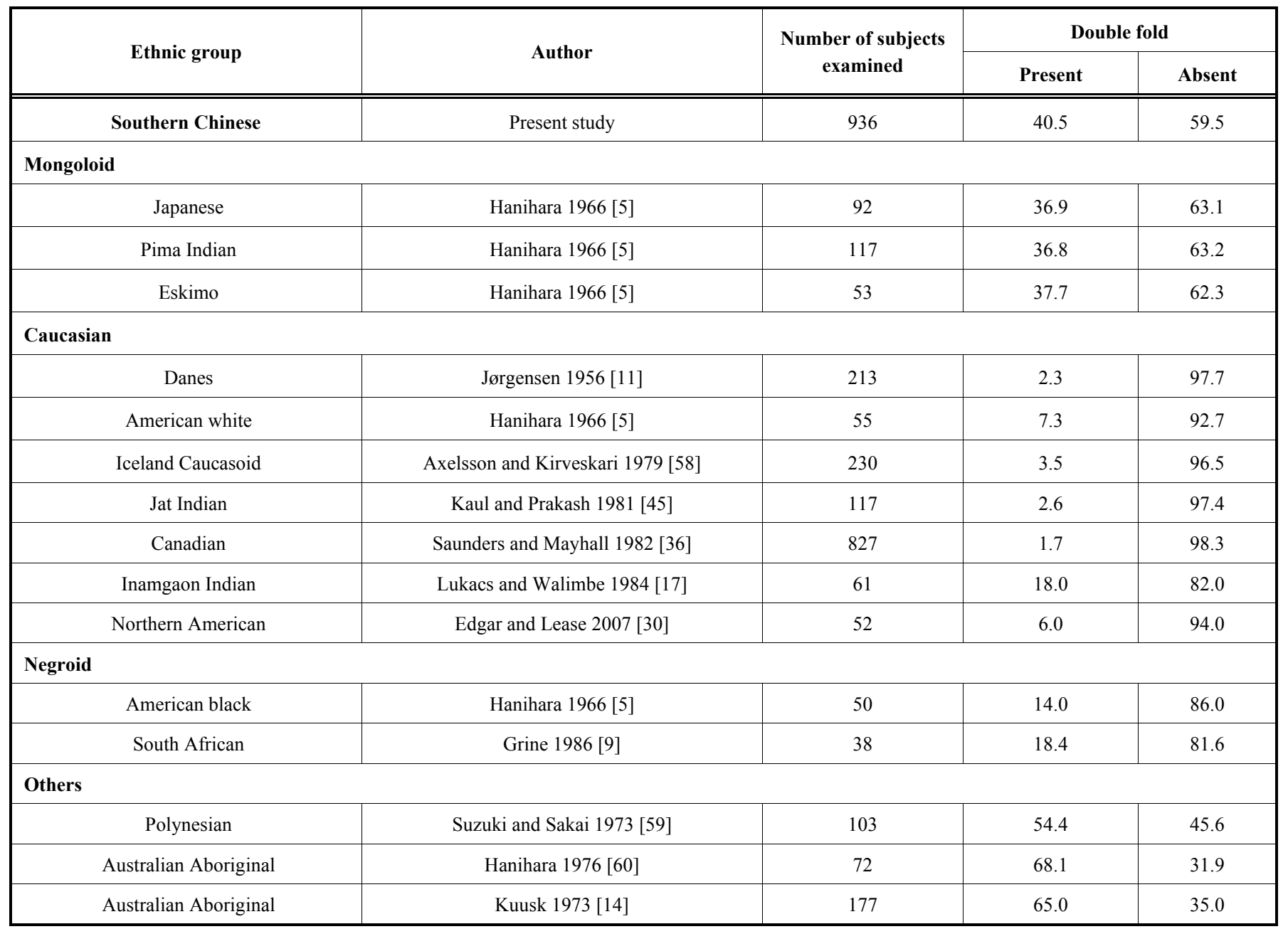

the primary teeth of southern Chinese would suggest that it is characteristic of this dentition.

\section{Deflecting Wrinkle}

This trait, also termed the metaconid medial occlusal ridge, was first described by Weidenreich [20] and has been found in both fossils and modern man and in anthropoids [39]. The wrinkle emerges from the tip of the metaconid, extends in the direction of the protoconid where it forms a right angle as it traverses the groove between the protoconid and the hypoconid, and meets the mesial wrinkle of the entoconid approximately in the center of the occlusal surface of the primary mandibular second molars. According to Hanihara [4], deflecting wrinkle is the deflected configuration of the central ridge of the metaconid which shows a strong development in both length and breadth and curves distally at the central part of the occlusal surface to contact with the hypoconid.

Deflecting wrinkle has been reported to occur in many populations, the prevalence figures are summarized in Table 10. These data show that Mongoloids have consistently high prevalence figures $(67.9 \%$ to $84.3 \%)$, while prevalence figures for Caucasians and Negroids are more variable. The deflecting wrinkle has been considered to be an inter-race variable characteristic and to form part of the Mongoloid dental complex [5]. This is supported by the high prevalence (74.2\%) among native Americans, who have been considered to be of Asian origin [18]. However, it should be noted that the sample size for this skeletal sample was small. The prevalence of deflecting wrinkle in the mandibular second molars was $63.0 \%$ which is slightly lower than for other Mongoloids (Table 10).

\section{Distal Trigonid Crest}

The distal trigonid crest was originally reported by Weidenreich [20], who observed this crest on the mandibular second molars of Sinanthropus Pekinensis. The distal trigonid crest [20], or hintere trigonidleiste (Remane 1952) [46] is the crest that connects the tip of the metaconid with the protoconid without interruption, so that the occlusal surface is clearly divided into two parts, the trigonid and the talonid. These characteristics form the basis of Hanihara's classification [4]. Korenhof [47], who studied the primary mandibular molars in Javanese identified six types of distal trigonid crests.

This crest is rarely observed in the primary dentition of modern man; however, it was included in this study because of its association with molarization of the human dentition. It 
Table 9. The Prevalence, Expressed as a Percentage, of the Seventh Accessory Cusp Trait on the Primary Mandibular Second Molars in Published Studies

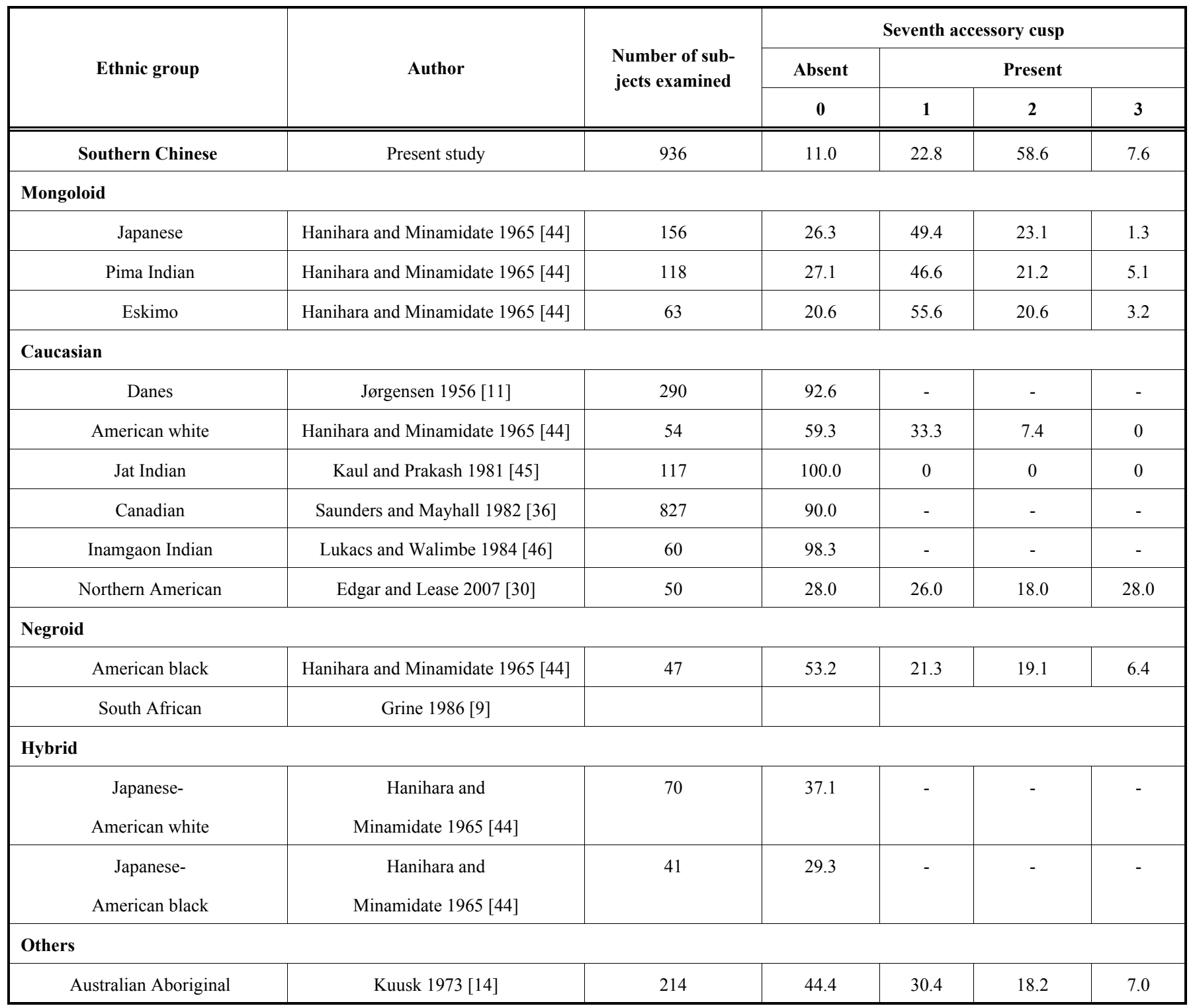

$0=$ no trace of seventh accessory cusp trait, $1=$ groove, $2=$ cusp-like formation, $3=$ cusp.

is thought that there may be a relationship between this crest and the well-developed central ridge of the metaconid [11, 39]. Furthermore, the deflecting wrinkle may be part of the original trigonid crest [39]. The trigonid crest has been clearly observed in the mandibular molars of the primitive Eocene primates, Australopithecus and Sinanthropus. However, the rarity of this crest on the mandibular molars of modern man suggests an evolutionary decline of this characteristic.

Distal trigonid crest has a reported prevalence ranging from 2.4\% to $17.8 \%$ for Mongoloids [4] and $13.4 \%$ for Australian Aboriginal [14], while it has not been reported in the primary dentition of Caucasians and Negroids [4], see Table 11. These data are indicative of a trait that can be considered as an inter-race variable characteristic with an affinity for Mongoloids [14]. The prevalence of distal trigonid crest in the mandibular second molar found in this study was $33.6 \%$ which was even higher than for other Mongoloids. Therefore, it could be regarded as characteristic of the primary dentition of southern Chinese children.

\section{Metaconid Ridge}

The metaconid ridge trait is formed by a well developed central ridge on the metaconid of the mandibular second molar. The central ridge of the metaconid is developed to a greater extent in both length and breadth than the central cusp ridges. The central ridge of the metaconid may be straight, and may exhibit a deflection distalwards. Where the metaconid ridge is deflected the structure becomes homologous with the deflecting wrinkle [4].

The metaconid ridge and the deflecting wrinkle although classified as two separate traits do occur on the same structure. The classifications for these two traits are based upon the size and shape of the metaconid ridge. The metaconid 
Table 10. The Prevalence, Expressed as a Percentage, of the Deflecting Wrinkle Trait on the Primary Mandibular Second Molars in Published Studies

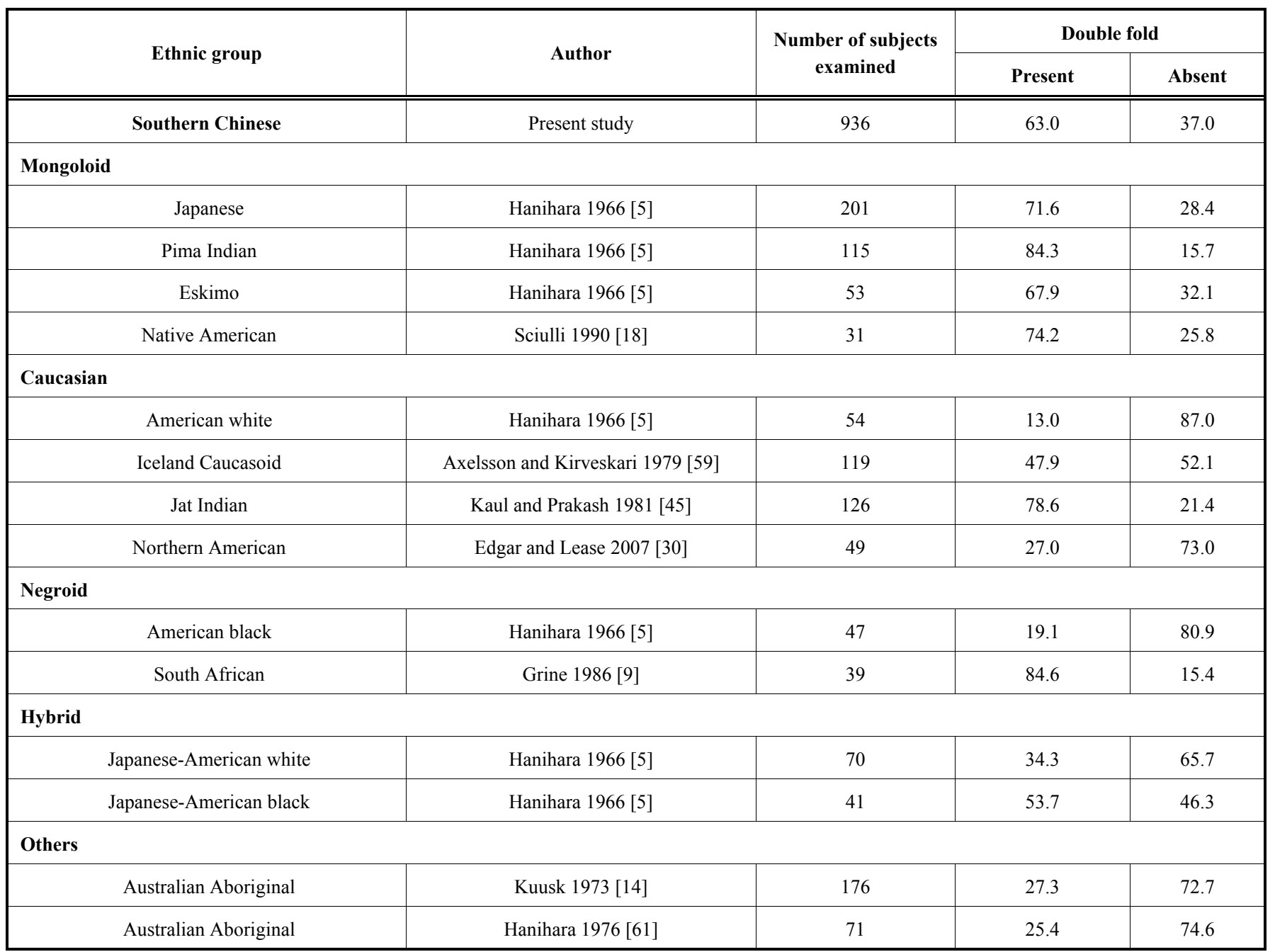

Table 11. The Prevalence, Expressed as a Percentage, of the Distal Trigonid Crest Trait on the Primary Mandibular Second Molars in Published Studies

\begin{tabular}{|c|c|c|c|c|}
\hline \multirow{2}{*}{ Ethnic group } & \multirow{2}{*}{ Author } & \multirow{2}{*}{$\begin{array}{c}\text { Number of } \\
\text { subjects Examined }\end{array}$} & \multicolumn{2}{|c|}{ Double fold } \\
\hline & & & Present & Absent \\
\hline Southern Chinese & Present study & 936 & 33.5 & 66.5 \\
\hline \multicolumn{5}{|l|}{ Mongoloid } \\
\hline Japanese & Hanihara 1961 [4] & 134 & 2.4 & 97.6 \\
\hline Pima Indian & Hanihara 1961 [4] & 123 & 17.8 & 82.2 \\
\hline Eskimo & Hanihara 1961 [4] & 71 & 9.2 & 90.8 \\
\hline \multicolumn{5}{|l|}{ Caucasian } \\
\hline American white & Hanihara 1961 [4] & 61 & 0 & 100.0 \\
\hline \multicolumn{5}{|l|}{ Negroid } \\
\hline American black & Hanihara 1961 [4] & 38 & 0 & 100.0 \\
\hline \multicolumn{5}{|l|}{ Others } \\
\hline Australian Aboriginal & Kuusk 1973 [14] & 172 & 13.4 & 86.6 \\
\hline
\end{tabular}


Table 12. The Prevalence, Expressed as a Percentage, of the Metaconid Ridge Trait on the Primary Mandibular Second Molars in Published Studies

\begin{tabular}{|c|c|c|c|c|}
\hline Ethnic group & Author & $\begin{array}{c}\text { Number of subjects } \\
\text { examined }\end{array}$ & \multicolumn{2}{|c|}{ Double fold } \\
\hline \multicolumn{5}{|l|}{ Mongoloid } \\
\hline Japanese & Hanihara 1961 [4] & 134 & 58.0 & 42.0 \\
\hline Eskimo & Hanihara 1961 [4] & 71 & 73.0 & 27.0 \\
\hline \multicolumn{5}{|l|}{ Caucasian } \\
\hline American white & Hanihara 1961 [4] & 61 & 11.0 & 89.0 \\
\hline \multicolumn{5}{|l|}{ Negroid } \\
\hline Japanese-American black & Hanihara 1961 [4] & 41 & 53.7 & 46.3 \\
\hline \multicolumn{5}{|l|}{ Others } \\
\hline Australian Aboriginal & Kuusk 1973 [14] & 181 & 27.6 & 72.4 \\
\hline
\end{tabular}

Table 13. The Frequency of Various Traits in the Primary Dentition of Southern Chinese People, other Mongoloid Groups and Caucasians

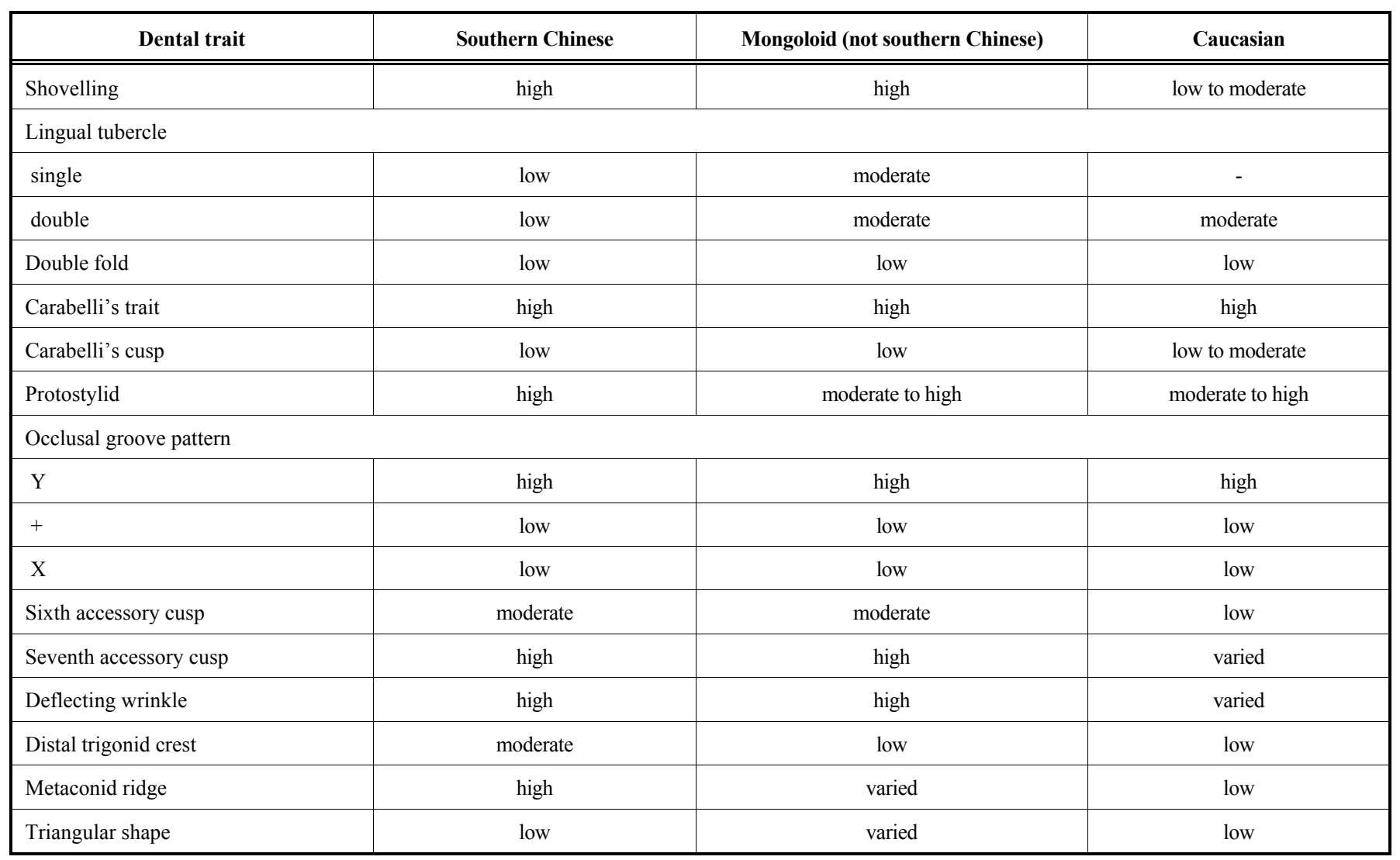

Chance of occurrence:

low: $\quad<30 \%$

moderate $\quad 30 \%-60 \%$

high: $\quad>60 \%$ 
ridge must be strongly developed to be classified as the metaconid ridge trait, while the deflecting wrinkle trait occurs only when the metaconid ridge is deflected.

The data in Table $\mathbf{1 2}$ show a much higher prevalence for the trait in Japanese $(58.0 \%)$ than in American whites $(11.0 \%)$ and American negroes $(20.0 \%)$ but not as high as for Pima Indian (84.0\%). The trait has been considered to be an inter-race variable characteristic and to form part of the Mongoloid dental complex [48]. The prevalence figure for metaconid ridges in the mandibular second molars in this study was $86.6 \%$ which is slightly higher than for other Mongoloids $(58.0 \%-84.0 \%)$. From these data, it appears that this trait can be regarded as characteristic of the primary dentition of southern Chinese children.

\section{Triangular Shape}

The primary mandibular first molar generally has fours cusps. However, in some instances, there is a tendency for fusion of the metaconid and the entoconid; consequently, the occlusal surface pattern appears triangular in shape [4].

The prevalence of the triangular shape trait for Caucasian-Americans has been reported to be 2 to $3 \%[11,49]$. The mandibular first molars of Caucasians rarely show the tendency towards fusion of the metaconid and the centoconid [50], and this feature has been reported to be completely absence in South African blacks [9]. However, approximately $20 \%-60 \%$ of native American populations and approximately $80 \%$ of Japanese children exhibit the triangular shape trait [4, 49]. While in the primary dentition of a late Archaic population in Ohio (native Americans) a prevalence of $16.7 \%$ was found [18]. The prevalence of triangular shape mandibular first molars found in this study was $17.5 \%$ which was higher then for Inamgaon Indian children (4.2\%) [17] and much lower than for Japanese children. From the published data, there appears to be a trend for Mongoloids to exhibit this trait; however, further studies in different racial groups are required to substantiate these findings.

Even though as a result of this study data have been complied on the prevalence of dental traits in the primary dentition of southern Chinese children, the limited published literature about these characteristics of the primary dentition indicates that there is a need for further research in this field to provide high quality prevalence data and supplement the anthropologic significance of the dental traits that have been observed in the primary teeth of the southern Chinese children.

\section{CONCLUSION}

From the findings of this study it has been determined that southern Chinese children have a higher prevalence of shovelling, protostylid, seventh accessory cusp, deflecting wrinkle, distal trigonid crest, metaconid ridge and triangular shape in the primary dentition than Caucasians. The prevalence figures for seventh accessory cusp, distal trigonid crest and metaconid ridge were so high that it may be appropriate to consider these traits as being characteristics of the southern Chinese dentition.

\section{REFERENCES}

[1] Biggerstaff RH. Cusp size, sexual dimorphism, and heritability of cusp size in twins. Am J Phys Anthropol 1975; 42: 127- 40.
[2] Corruccini RS, Sharma K, Potter RHY. Occlusal genetic variance and heritability in twins. Am J Phys Anthropol 1986; 70: 293-9.

[3] Hanihara K. Some crown characters of the deciduous incisors and canines in Japanese hybrids. J Anthropol Soc Nippon 1965; 72: 111.

[4] Hanihara K. Criteria for classification of crown characters of the human deciduous dentition. J Anthropol Soc Nippon 1961; 69: 2745 .

[5] Hanihara K. Mongoloid dental complex in the deciduous dentition. J Anthropol Soc Nippon 1966; 74: 9-20.

[6] Hanihara K. Studies on the deciduous dentition of the Japanese and the Japanese-American hybrids. III. Deciduous lower molars. J Anthropol Soc Nippon 1956; 64: 95-116.

[7] Hanihara K. Morphological pattern of the deciduous dentition in the Japanese American hybrids. J Anthropol Soc Nippon 1968; 76: 114-21.

[8] Hanihara K. Crown characters of the deciduous dentition of Japanese-American hybrids. Dental Anthropology. Oxford: Pergamon Press 1963; 105-24.

[9] Grine FE. Anthropological aspects of the deciduous teeth of South African Blacks. In: Singer R, Lundy JK, Eds. variation, culture and evolution in african populations. Johannesburg: Witwatersrand University Press 1986.

[10] Hellman M. Racial characters in the human dentition. Proc Am Philos Soc 1928; 67: 157-74.

[11] Jøgensen KD. The deciduous dentition: a descriptive and comparative anatomical study. Act Odont Scand 1956; 14(Suppl 20): 1-202.

[12] Scott GR. Classification sex dimorphism, association, and population variation of the canine distal accessory ridge. Hum Biol 1977; 49:453-69.

[13] Scott GR. Population variation of Carabelli's trait. Hum Biol 1980; 52: 63-78.

[14] Kuusk S. Deciduous tooth crown morphology in a tribe of Australian Aborigines. MDS Thesis, Department of Restorative Dentistry, University of Adelaide 1973.

[15] Hrdlička A. Shovel shape teeth. Am J Phys Anthropol 1920; 3 : 429-66.

[16] Tratman EK. A comparison of the teeth of people of IndoEuropean with Mongoloid racial stock. Dent Rec 1950; 70: 31-53, 63-88.

[17] Lukacs JR, Walimbe SR. Deciduous dental morphology and the biological affinities of a late chalacolithic skeletal series from western India. Am J Phys Anthropol 1984; 65: 23-30.

[18] Sciulli PW. Deciduous dentition of a Late Archaic population of Ohio. Hum Biol 1990; 62: 221-45.

[19] Adloff P. Der Eckzahn des Menschen und des Abstammungsproblem. Z Anat Entwgesch 1931; 94: 94-116.

[20] Weidenreich F. The dentition of Sinanthropus pekinensis: a comparative odontograph of the hominids. Palaeont Sinica 1937; 10.

[21] Hrdlička A. Future studies on tooth morphology. Am J Phys Anthropol 1921; 4: 141-76.

[22] Hanihara K. Studies on the deciduous dentition of the Japanese and the Japanese-American hybrids. II. Deciduous canines. J Anthropol Soc Nippon 1955; 64: 63-82.

[23] Robinson JT. The dentition of the Australopthecinae. Transvaal Museum Memoir 1956; no. 9, Pretoria.

[24] Dietz VH. A common dental morphotropic factor, the Carabelli's triat. J Am Dent Assoc 1944; 31: 784-9.

[25] Kraus BS. Carabelli's anomaly of the maxillary molar teeth. Am J Hum Genet 1951; 3: 348-55.

[26] Meredith HV, Hixon EH. Frequency, size and bilateralism of Carabelli's tubercle. J Dent Res 1954; 33: 435-50.

[27] Dahlberg AA. Analysis of the American Indian dentition. Dental Anthropology. London: Pregamon Press 1963; 149-77.

[28] Dahlberg AA. The changing dentition of man. J Am Dent Assoc 1945; 32: 676-90.

[29] Dahlberg AA. In: Brothwell DR, Ed. The dentition of the American Indian. Papers on the Physical Anthropology of the American Indian. Laughlin WS, Ed. New York: The Viking Fund 1951; 138-76.

[30] Edgar HJ, Lease LR. Corrections between deciduous and permanent tooth morphology in a European American sample. Am J Phys Anthropol 2007; 133(1): 726-34.

[31] Bolk L. Problem of human dentition. Am J Anat 1917; 19: 91-148.

[32] Dahlberg AA. The evolutionary significance of the protostylid. Am J Phys Anthropol 1950; 8: 15-25. 
[33] Gregory WK. Studies on the evolution of the primates. Bull Am Museum Nat History 1916; 35: 239-355.

[34] Turner CG. The dentition of the Arctic people. PhD Thesis, University of Wisconsin, Madison 1967.

[35] Turner CG. New classifications of non-metrical dental variation. Am J Phys Anthropol 1970; 33: 144-5.

[36] Saunders SR, Mayhall JT. Developmental patterns of human dental morphological traits. Archs Oral Biol 1982; 27: 45-9.

[37] Sahiki M, Tashiro K, Hayama S. Morphological study on the dentition of the macaque, (1) Morphology of molars. J Jpn Stomatol Soc 1961; 28: 81-100.

[38] Weidenreich F. Giant early man from Java and South China. Anthrop Pap Am Mus Nat Hist 1945; 40: 1.

[39] von Koenigswald GHR. Gigantopithtcus blacki von Koenigswald, a giant fossil hominoid from the Pleistocene of Southern China. Anthropol Pap Am Mus Nat Hist 1952; 34: 4.

[40] Selenka E. Rassen, Schädel und Bezahnung des Orangutan. Menschenaffen (Anthropomorphae) Wiesbaden 1989; Part 1: 1-91.

[41] Schwalbe G. Über den fossilen Affen Oreopithecus bambolii. Zugleich ein Beitrag zur Morphologie der Zähne der Primaten. Z Morp Anthrop 1916; 19: 149-254.

[42] Robinson JT. Meganthropus, australopithecines and hominid. Am J Phys Anthropol 1953; 11: 1-38.

[43] Scott GR, Turner CG. The anthropology of modern human teeth dental morphology and its variation in recent human populations. Cambridge: Cambridge University Press 1997; 216-8.

[44] Hanihara K, Manamidate T. Tuberculum accessorium mediale internum in the human deciduous lower second molars. J Anthropol Soc Nippon 1965; 73: 9-19.

[45] Kaul V, Prakash S. Morphologic features of Jat dentition. Am J Phys Anthropol 1981; 54: 123-7.

[46] Remane A. Der Vordere Prämolar (P3) von Australopithecus Prometheus und die morphologisch Stellung des Australopithecinengebisses. Z Morph Anthropol 1952; 43: 288-310. cited by Hanihara (1961).

[47] Korenhof CAW. Evolutionary trends of the inner enamel anatomy of deciduous molars from Sangiran, Java, Indonesia. In: Kurtén B,
Ed. Teeth: Form, Function and Evolution. Columbia University Press 1982; 350-5.

[48] Hanihara K. Racial characteristics in the dentition. J Dent Res 1967; 46: 923-6.

[49] Dahlberg AA. The dentition of the American Indian. In: Laughlin WS, Ed. The Physical Anthropology of the American Indian. New York: The Viking Fund 1949; 138-76.

[50] Brabant H. Comparison of the characteristics and anomalies of the deciduous and the permanent dentition. J Dent Res 1967; 45: 897901.

[51] Escobar V, Conneally PM, Lopez C. The dentition of Queckchi Indians. Anthropological aspects. Am J Phys Anthropol 1977; 47: 443-52.

[52] Ooshima T, Ishida R, Mishima K, Sobue S. The prevalence of developmental anomalies of teeth and their association with tooth size in the primary and permanent dentitions of 1650 Japanese children. Int J Paediatr Dent 1996; 6: 87-94.

[53] Joshi MR. Carabelli's trait on maxillary second deciduous molars and first permanent molars in Hindus. Archs Oral Biol 1975; 20 699-700.

[54] Reddy VR. Carabelli's anomaly in a Karnataka town of south India. Acta Anthropogenet 1983; 7(1): 53-74.

[55] Kieser JA. An analysis of the Carabelli trait in the mixed deciduous and permanent human dentition. Arch Oral Biol 1984; 29(6):403-6.

[56] Kannapan JG, Swaminathan S. A study on a dental morphological variation. Tubercle of Carabelli. Indian J Dent Res 2001; 12(3): 145-9.

[57] Townsend GC, Brown T. The carabelli trait in Australian Aboriginal dentition. Archs Oral Biol 1981; 26: 809-14.

[58] Axelsson G, Kirveskari P. Sixth and seventh cusp on lower molar teeth of Icelanders. Am J Phys Anthropol 1979; 51: 79-82.

[59] Suzuki M, Sakai T. Occlusal surface pattern of the lower molars and second deciduous molars among the living Polynesians. Am J Phys Anthropol 1973; 39: 305-16.

[60] Hanihara K. Statistical and comparative studies of the Australian aboriginal dentition. Bulletin of the University Museum, University of Tokyo 1976; vol. 11: pp. 1-57. 